\title{
Hou Hsiao-hsien's The Puppetmaster
}

\author{
By Yvonne Ng \\ Spring 1999 Issue of KINEMA \\ ESSENCE AND ELLIPSIS IN HOU HSIAO HSIEN'S THE PUPPETMASTER
}

THE Puppetmaster (Hsimeng Rensheng, 1993), about the life of veteran puppeteer Li Tienlu, is a groundbreaking film by one of Taiwan's foremost director Hou Hsiao-hsien. The biographical film portrays Li's early life from his birth in 1909 until 1945, when fifty years of Japanese rule on the island came to end. Li, whom the director calls "a living encyclopaedia of Chinese tradition"(1) is seemly regarded as a "national treasure." No stranger to Hou's films, Li has appeared in several of the director's works since Dust in the Wind (1986). Hou's themes are rooted in the daily lives of the Taiwanese, particularly rural life. His films have a nostalgic look to them but at the same time, an unmistakable feel of authenticity and originality born from a realist approach executed in a surprisingly stylized manner.

In the film, Li Tienlu's account of his turbulent life and career is also an account of Taiwan's modern history and a reflection of its culture. Conceived as part of a trilogy dealing with Taiwan's history in this century, The Puppetmaster is chronologically the first in the series, the second being the earlier The City of Sadness (Pei chi'ing Ch'eng-shi, 1989) depicting a family's fate during the transfer of the island back to Chinese hands from 1945-49, and the $28^{\text {th }}$ February Incident which saw the massacre of Taiwanese by government troops in 1947. The film was awarded the Golden Lion at the 1989 Venice International Film Festival. The last film in the trilogy, Good Men, Good Women (Haonan, Haonü, 1995), looks at a man who was imprisoned due to the $28^{\text {th }}$ February Incident and his experiences upon his release into modern Taipei in 1987.

Hou has often been compared to the Japanese director Yasujiro Ozu and the French director Robert Bresson for his minimalist and elliptical narrative style. In The Puppetmaster, however, Hou seems to have moved a step closer to what J. Hoberman hails as "a rebirth of cinema itself."(2) The complex aesthetics of The Puppetmaster in its realist principles, its elliptical and multi-layered narrative, its evocative images and sounds, and its novel use of voice-over narration, have opened new horizons for communicating through the film medium. Hou's film demands the active engagement of a viewer in a continuous process of interpretation, imagination, and recollection. If it seems a lot to ask for from the viewer, it is because the film has so much to offer. Hou explains: "I only want to guide my audience into a situation where, hopefully...what is shown on the screen may cause them to reflect deeply about human lives." (3)

Photographed in Fuzhou, capital of Fujian Province in south-east China and in Taiwan, the film deals with thirty years of history in two hours and twenty-two minutes. According to Hou, he felt burdened by the initial number of dramas and characters. He decided to focus instead on the essence of relationships through

a narrative structure of ellipsis. ${ }^{(4)}$ Hou likens this structure to traditional Chinese opera. "It simply gives you a scene without much of a clear narrative, unlike Western drama where all the elements must be put in place. Ellipsis and other indirect narrative methods are, ironically, more clear-cut and to the point. It all depends on how you master these methods." ${ }^{(5)}$ The result of ellipsis in The Puppetmaster is what Taiwanese film critic Peggy Chiao calls a step closer to "an austere and pure cinema." ${ }^{(6)}$ What follows is an attempt to explore how the themes and meaning of The Puppetmaster are illuminated and enriched by the film's unique narrative style and structure.

The themes of The Puppetmaster are suggested by the film's Chinese title which literally means "Drama, Dream, Life." Hou has commented that his purpose in making the film is to show the Chinese way of thinking and philosophy of life through the person of Li Tienlu. Li, the director believes, "preserves the values of traditional drama within himself," a system of values derived from a combination of Confucianism, Taoism and Buddhism, "the three pillars of Chinese thinking." (Cinemaya, 4) Through its effort to capture and preserve the essence of Chinese-ness, the film has also become a document on the rituals and traditions of a bygone era, increasingly lost to a Westernising and materialistic society. Through portraying the art, life and relationships of the puppetmaster Li Tienlu, the film also evokes the interdependence between art and life and the dream-like quality shared by both. 
In The Puppetmaster the plot is divided into three main segments. The first part deals with Li's life at home and his relationships with family members. The middle section depicts his relationship with a prostitute, Leitzu and the third part shows his experiences in the Japanese propaganda unit as its chief puppeteer as well as his family's evacuation tribulations. At the same time, the film weaves three points of view: Li's testimony of his life up to 1945 through voice-over narration and his on-screen presence; Hou's representation of Li's life, and the theatrical performances that display Li's art. Peggy Chiao observes that "the three perspectives are complementary; sometimes there is a connection, at other times they are mutually exclusive, even contradictory. The repetition and comparison of the three perspectives are really an artistic, 'fictional' intervention. It outlines the inherent cinematic nature of The Puppetmaster which, like A City of Sadness, springs forth to the foreground." (7) The combination of meta-cinematic elements and the documentary flavour of the film makes for an intriguing emulsion of fiction and documentary. In this film, Hou has also refrained from employing the conventions of classical Hollywood cinema, rejecting a plot with the usual conflict, climax and resolution framework in favour of a loose narrative causality and ellipsis.

Although the film is about the early life of Li Tienlu, the narrative is not so much focussed on him than centred around him. It is through the vignettes depicting his relationships with his grandfather, mother, father, stepmother, his mistress, and the Japanese that we gain some understanding of Li's character and his relationship to his art. This perception is enhanced by the presence of Li himself as the film's raconteur, now an elderly gentleman but very much alert with an air of the born survivor.

The film begins with the opening credits over which the sound of traditional Chinese music is heard. The music suggests the beginning of a performance which continues to play as the introductory intertitles establish the film's historical context, explaining how China ceded Taiwan to the Japanese after the 1895 Sino-Japanese war, beginning fifty years of Japanese rule on the island until the end of the Second World War. As the first shot fades in, we see a family and some guests around a dining table presided over by the patriarch, Li Tienlu's maternal grandfather, at the centre. They are discussing the coming celebrations for Li's first birthday. Behind them is the family altar with lit candles. Li's father Ko Mangdang, with his back to the camera, is busy pouring tea for the group. One of the guests is addressing another person who can be partially seen on-screen. Li's mother comes into the room with the baby followed by other women. Everyone fusses over the child, and grandfather eagerly carries his grandson. A guest remarks on the baby's "big face", an auspicious trait. Meanwhile, Li's distinctive voice-over narration begins with his characteristic introduction, "To speak of man's fortunes..." a phrase underlying his profound belief that life is subject of fate and that human beings must ultimately reconcile themselves to their destinies.

The viewer finds out that because Li's father had married into his mother's family, Li therefore came to possess his mother's surname instead of his father's. Moreover, due to the advice of a fortune-teller who predicted that Li would have a difficult life, he had to call his father "uncle" and his mother "aunt" in order to counteract his bad fortune and the impact on the family. It is indicative of Hou's style that Li's voice-over narration does not simply explain what is shown on the screen but he elaborates on details which are never shown to the viewer. For example, Li tells us while we are watching the happy family scene, that his birth had in fact triggered a dispute between his grandfather and father, both of whom wished to register the baby in their respective surnames. This revelation adds another dimension to the truth of the scene we are witnessing. Reality has more layers than can be revealed in a shot. The viewer is distanced from the action on one level through the presence of the voice-over narration and on another by the content of the narration itself which in this scene, presents a gentle ironical contrast to the image.

This scene is interesting since it immediately sets the tone for the historical, social and cultural perspective of the film. The year is about 1910 when the Taiwanese men still wore pigtails. The focus on the family, the authority of the grandfather and the discussion of celebrations for the grandson highlight the nature of the traditional Chinese family with its patriarchal system. The atmosphere is warm and animated, accentuated by the earth-toned colours and diffuse lighting. Here, as in the rest of the film, the director uses a camera position that is no closer to the actors than a medium or a medium-long shot. The physical distance allows the viewer to observe the relationships among the characters in the context of their surroundings. The life of the Puppetmaster is understood and defined by his relationships with his family, his friends, his art and environment. 
Hou's preference for a fixed camera suggests a deep respect for the actors. It is as if he is reluctant to intrude into the personal space of the characters, preferring to observe their actions as one would in daily interaction with others, from a socially acceptable distance. Although the University of Hawaii Professor Graham Parkes is referring to the Japanese when he remarks that it is a "culture that prizes allusive understatement and subtle indirectness in human intercourse"(8) (Graham Parkes, Japanese philosophy, Oxford Companion to Philosophy, p.426), he could just as well have been speaking of the Chinese. Hou's preference for the distanced approach in filmmaking seem to stem in part from his own personality but also to a significant degree from social and cultural influences. His use of ellipsis and off-screen space, absence of close-ups and melodrama gives his films a subtle force and a sense of restraint, characteristics which are also admired in Chinese culture.

Hou's off-screen space aesthetics points to the style of the Japanese director Ozu even though Hou claims he had never seen an Ozu film when he started to use the technique. In employing off-screen space, the director extends the filmic space beyond the borders of the film frame to imply the continuity between the action on the screen and the outside world. The borders of the film frame thus serve as a "window on life." Indeed Hou's frequent use of deep focus and long takes further reinforces this realist underpinning in his films. Hou's style shows influence of Chinese landscape painting. To better understand what impact this influence might have on Hou's film, it is useful to recall some of the principles of this art. In defining the aims of the Chinese landscape painter, the Sinologist Michael Sullivan explains: "The composition of a Chinese painting is not defined by the four walls of its mount as is a European painting within its frame...Rather is his picture...a fragment - chosen as it were at random, yet profoundly significant - of eternity." ${ }^{(9)}$

Thus an aim of Chinese landscape painting is to show the essence of the scene.

We are often told that the Chinese painter leaves large areas of the picture space empty so that we may "complete it in our imagination." But that is not so. The very concept of completion is utterly alien to the Chinese way of thinking. The Chinese painter deliberately avoids a complete statement because he knows that we can never know everything, that what we can describe or "complete," cannot be true except in a very limited sense... His landscape is not a final statement but a starting point; not an end, but the opening of a door. (10)

The traditional family occasion cuts to an establishing shot of a children at play and people watching an outdoor puppet theatre performance. We see the source of the music from the opening scene as an exquisitely elaborate facade of a puppet theatre fills the frame of the film screen. In a series of ritual bowing, the personification of the three Chinese deities of Good Fortune, High Office and Longevity announce that the ceremonies have come to an end. The puppeteer's arm and white sleeve is exposed as he lifts the puppets above the stage to represent the gods flying up to the heavens. The self-reflexivity of the spectacle adds an element of surprise to the performance while allowing the audience to appreciate all the more the puppeteer's skill in creating a hypnotic illusion of reality. Whatever one may think of the significance of this scene, it is a loving presentation of the art and craft of the puppet theatre. The depiction of theatrical performances in The Puppetmaster serve as punctuation marks signalling a change of phase in Li's life. It is only at the end of this puppet performance that the title of the film is announced. What follows is the end of a toddler's idyllic existence and the beginning of the loss of innocence.

In the ensuing scene, we see a long shot of a boy of about six or seven-years old standing by the teacher in the front of the class while his classmates recite verse. Closer to the camera, a man sits in the shadows, smoking his pipe and silently watching the class. The viewer is left in some suspense over the ambiguity of this shot. However, if one were to observe the action carefully, one would see next an extreme long shot of a path in the fields on which a man is walking from the bottom right of the scene to the upper left of the picture trailed by a boy whom he cuffs on the head just before they disappear out of the frame. The viewer has yet to be told a single word about the meaning of all this but it is clear that the man is displeased with the boy. In this subtle fashion, the director raises questions in the minds of the audience.

Back at home in the same dining room where the family had discussed plans for baby Li's first birthday, we discover that the boy Li had stolen some calligraphy books and had been punished right in front of his grandfather. He is severely reprimanded by his grandfather and his father whose voice is heard from off-screen. His grandmother tries to console the boy while his mother ignores him as she prepares the table 
for the family meal. In the next scene, on the upper level of the house, the boy Li is seen alone kneeling on the boards of the room reflecting on his misdeed. Hearing footsteps coming up the stairs, he immediately straightens from his slouching position. His mother comes into the room matter-of-factly, takes out a cane and proceeds calmly to use it on her son. The boy stoically suffers his punishment with only the faintest of whimpers, indicating already at this tender age, a sign of the born survivor.

By compressing time through the elliptical narrative, Hou allows this sombre sequence from the school to the caning at home to be juxtaposed vividly with the film's vibrant first scene when the boy Li had received more favourable attention from the family. The contrast in scenes is a reflection on the inevitability of change and of searing moments remembered from childhood. The colour scheme of the two scenes present a visual contrast as well. Whereas the first family scene is brightly lit in warm tones, the chastisement scene which is also in the same room contains primarily grey and blue hues. We see the latter scene in a longer shot than the first one so that the boy standing before his grandfather seems even more lost and isolated in the room.

The traditional Chinese attitude towards authority is neatly depicted when two Chinese officers in the service of the ruling Japanese government appear at the Li household to order the men to cut off their pigtails which had been the customary fashion of males in the Ching Dynasty. For doing this, the men receive tickets for a Chinese opera performance. Li's grandfather, though taken aback by this order, maintains a respectful demeanour towards the officers and accepts the tickets. Li's father, Ko Mangdang, on the other hand, concedes to do the inevitable but brusquely snubs at the compensation. This small act of rebellion is left unexplained but it is interesting to learn as the film progresses that Mangdang is also a puppeteer. One may conjecture he simply refuses to be treated like a child in being appeased for what is essentially an act of humiliation or possibly as an artist, he is more sensitive to the use of art for purposes other than for its inherent value.

One of the most subtle examples of mise-en-scène in the film is the scene where a male audience is watching a Chinese opera performance in which two actors are displaying their physical dexterity and swordfighting skills. The camera is placed in a fixed position behind the opera audience so that we have a full view of the action on stage as well as the movements of the audience sitting below. Other than the fact that the audience is being supervised by a police officer, the show resembles any other regular performance. Soon however, another officer moves into the frame from the right with a man who seems to be busy doing something. Before we realise what has happened, a member of the audience in the last row has unsuspectingly had his pigtail snipped off and deposited into a big basket carried by the police officer. The audience only realises this when the man who wore the pigtail suddenly turns around in surprise to find most of his hair gone as the officer and the barber unobtrusively move on to do their job on the next unsuspecting spectator. All this while, the operatic feats on stage are being performed without incident.

This is an inspired scene with a wry sense of humour which is only available to film viewers who have also been observing the movements of the audience. Rather than directing the viewer's attention through closeups and montage, Hou has designed this scene entirely in long shot and deep focus to give the viewer ample time and freedom to look at whatever interests him or her. In setting the cutting of the pigtails against the backdrop of a swordfight display, the director makes an ironical comment on the unexpected drama amidst the audience which is certainly more crude and heavy-handed than the action on stage. It is interesting that most of those whose hair had been deprived by the barber in the theatre continue to watch the show without protest. This attitude attests perhaps, to the hypnotic quality and popularity of the opera performances, but it also suggests a general docility towards state authorities as well as resignation to one's lot.

Throughout the film, Hou communicates the puppetmaster's memories in an elliptical fashion. In telling us about the demise of Li's family members, for instance, the sentimental or melodramatic potential of such scenes is intentionally avoided by not showing the deaths at all, in contrast to the classical Hollywood style. Instead the poignancy of these stories tend to come from the tension in contrasting the image of that particular person going about his or her daily routine with the narration of how that person died. An example is the tale of Li's mother's death which occurred when he was only eight years old.

After the vignette from the previous scene, there is transitional shot of a rural landscape in extreme long shot. In the film, Hou regularly employs rural landscapes to depict the passing of time. In these scenes, the extreme long shot mimics the perspective of Chinese landscape paintings. Roads and paths cut diagonally 
across the frame and human figures and carriages seem engulfed by the open space, perhaps prompted by an underlying philosophy which seeks to place people in perspective with respect to nature. Hou's landscapes are also atmospheric. In this instance, smoke rising from burnt offerings along the sides of the road create a lyrical and nostalgic effect, as if it were an image from the depths of memory. Indeed, "smoke is a symbol of transitoriness: it rises quickly and disperses just as quickly." (11)

Elsewhere in the film, the director shows Li's grandparents burning joss sticks at the altar table. Just then, Li's mother enters the house with her husband looking tired and withdrawn. She climbs slowly up the stairs to her bedroom, passing through the hallway in which she had caned her son. In her own room, she sits before her mirror and combs her hair. Dressed in black, she presents a sombre portrait of a woman who, though still relatively young, has forever lost the bloom of vitality. While the camera focuses on Li's mother, Li notes in his narration that in life "the hardest things are separation and death." He relates the story of how his mother had prayed to the gods to take her life in exchange for her mother's as the latter had been very ill. As if the gods had heard her plea, Li's grandmother recovered but his mother contracted tuberculosis shortly after. She was released from hospital just when the Festival of the Hungry Ghosts was approaching. Efforts to build up her appetite were of no avail and she died soon after consuming the soup made from the duck offering to the spirits. The beginning and end of this sequence are marked by images of carriages travelling through the country roads, evoking the idea of life as a passage in time. The occult background events accompanying Li's mother's death are an illustration of the cultural specificity of the film which does not try to explain the beliefs and customs of the Taiwanese to the uninitiated. Although this may provide difficulties in understanding certain aspects of the film, being of the same culture is certainly not a criterion for appreciating the accomplishment of The Puppetmaster.

The scene of Li's grandfather's demise provides one of the most memorable examples of the off-screen space technique in the film. Grandfather Li is shown in a long shot coming out from his room and climbing down the stairs in a fit of coughing. Midway down the steps, the old man stumbles and falls out of the film frame as the camera remains focussed where he was. For the rest of the scene, all we see is the empty space describing, in the words of the director, "a very real presence of an absence" and the family's collection of ancestral portraits hanging by the stairs. These pictures suddenly acquire a startling significance through their connotation with death. Though we can no longer see the grandfather we can still hear him off-screen groaning at the bottom of the stairs and the early morning shuffling of footsteps as family members investigate the cause of the commotion. The insistent crowing of a rooster suggests the time of day and situates the accident in its rural environment even though we see only the dim interior of a house. This scene takes place entirely without dialogue or commentary and it is not until the following scene that explicit mention is made of the grandfather's death.

The direct cause of the death is clear enough but Hou also opens the possibility of an indirect cause that might have triggered the accident: the grandfather's despondent state of mind. The scene preceding his fall shows how and why his little granddaughter, Big Eyes, is taken away by her mother back to Amoy. Shot in one long take framed by a door, the viewer is shown a particularly poetic and melancholic tableau, marked by silence and muted colours. Li's grandfather is seen in profile, meditatively smoking his pipe, the drifting curls of smoke creating the only sense of movement in the still-life image. This moment of tranquillity turns into emotional agitation when he finds out that Ko Mangdang's new wife is mistreating Big Eyes and her cousin Li Tienlu. Grandfather had intended Big Eyes to be the future bride of Li but things seem to have changed beyond his control. Says Big Eyes' mother, "You should see it more positively. Take it as part of your fate." The scene ends in a moving parting between the grandfather and his granddaughter though it is far from being sentimental. The fixed medium-long shot ensures that we see the scene as if through a window and enables the audience to keep emotional objectivity. However, this does not prevent the audience from understanding the attendant feelings in such a situation. On the contrary, it is a scene which induces reflection through its evocative mise-en-scène and genuine poignancy.

On the other hand, Li's relationship with his stepmother, Lai Hwat, which is conspicuously lacking in warmth, is presented differently. The arrival of Lai Hwat into the household is depicted by the tradition of exchanging the children's old sashes for new ones brought by the stepmother, symbolising her new relationship with them. However, the defining moment of Li's misery with his stepmother is portrayed in the same room where he was once disciplined by his own mother, the location inviting a mental comparison of the motivation behind 
both women's actions. One year after his mother's death, the boy seems to have grown remote from his father as well. We see Li coming up the stairs with a bloodied nose and greeting his father who is having his meal. When his father demands to know who he has been fighting with, Li does not answer buts sits sullenly on the stairs where his grandfather had slipped. After his father leaves, Li starts to prepare his food. Lai Hwat pointedly treats the boy as if he did not exist. Annoyed by her attitude and demeanour, Li throws his bowl on the ground and leaves the room. His stepmother screams at him never to come back. We find out from the voice-over narration that Li's theatrical talent is recognised and soon finds a job with a travelling puppet theatre troupe before being poached by a rival troupe which staged its performances in the mountain villages. Even though only a teenager, $\mathrm{Li}$ is now helping to support his family and is even taking care of his grandmother who has come to live with him in the mountains. As the voice-over narration proceeds, the scene changes to a house undergoing construction in the hills, as if to suggest that new rooms are being built for the boy and his grandmother.

Unexpectedly, about fifty minutes into the film, we see Li Tienlu himself, now an elderly man, telling his story directly to the camera about how he took care of his grandmother's funeral. Sitting in front of the same house that is being extended, Li seems to be a link between the present and the past. In the style of a true raconteur, Li recounts the mysterious circumstances of his grandmother's death which are inextricably bound with Chinese superstitions and beliefs. Thus the narrator reveals and the filmmaker preserves a way of thinking which is still very much alive in present Chinese culture. What also emerges from this story is a perception of the artist as a young boy who is being moulded by the traditional beliefs and values of his own culture.

In trying to show the nature of relationships in life, we are given an elliptical view of the changing relationship between $\mathrm{Li}$ and his father Ko Mangdang. In one scene, Li, now a young adult, visits his parental home with a friend to ask for his father's permission to marry the daughter of his troupe manager, Ong Lai. Like his father, he would be marrying into his prospective bride's family, having no financial position of his own. Mangdang refuses and the two have a heated exchange before Li leaves in anger. In a few suggestive strokes, the next two scenes show that Li has proceeded with his marriage and that the wife is about to give birth as the household prays at the family altar in the courtyard.

In another scene, $\mathrm{Li}$ is in the shadowy interior of his father's house, the wooden beams and low roof creating a claustrophobic effect. The stepmother's scolding voice can be heard on the upper level. As Li takes a hand puppet out of a box, we hear his father's voice off-screen saying that the puppets need repainting as they have not been used for a long time. For the first time in the film, father and son are communicating. It is only at this point that we realize there has been a positive change in their relationship. Now in his early twenties, Li has formed his own puppet theatre troupe to be called "Also Like Life." Li explains to his father that it is a name chosen by an old man who said that "puppets in performance are like people. So puppet plays are also like life." This is of course one of the themes of the film, that life and drama are sometimes indistinguishable, separated only by the form and materials of the artist's craft. Peggy Chiao elaborates: "Each event and episode is recreated through the image; the narration uses different texts to reconstruct the existence of real people. Its dynamics and uncertain precision cause people to consider the corresponding relationships." (12)

In this scene, Mangdang's face remains hidden to the viewer. We only see his figure lying on his bed, indicating his state of health. Whereas both Mangdang and his wife had earlier adopted an opposing attitude towards Li, he now defends his son against the open hostility of his wife. Not long, after this, Li's father dies. Although filial piety is one of the most highly-regarded virtues in Chinese society, Li and his family are chased away by his stepmother at the father's wake, thus preventing him from observing the proper funeral rites.

The middle section of the film focuses on Li's relationship with Leitzu, a prostitute with whom he finds contentment. When the Sino-Japanese War broke out in 1937, all outdoor theatre plays were banned, thus effectively closing down Li's new puppet theatre. Li joins a Taiwanese opera troupe called Red Jade, moving south to Taiching to perform at the Happy Stage Theatre. It is there that he strikes up a relationship with Leitzu. Their relationship is portrayed in a series of vignettes endowed with the quiet beauty of cherished photographs. 
From narrating about how they first met before a performance one evening, the film cuts to a scene in the private room of the Cherry Garden brothel where Li and Leitzu are evidently already well-acquainted while Li's friend sits with them at the round dining table, teasing them while Li and Leitzu play at a cigarette-lighting game. His friend comments to Li that Leitzu seems in love with him.

Filmed in long shot, the interior of the room, including the lighting, suggests warmth and intimacy. There is a red lantern by the door, and a white lamp hanging above the table adds light and focus to the image. The atmosphere is one of subtle eroticism. Hou's economical use of sound is also apparent here as music from the previous scene flows into the present one, retaining the street flavour of the last scene in which $\mathrm{Li}$ asked some friends to shadow Leitzu home. At the same time, there is an overlapping stream of music from the radio in the room. At one point, Leitzu changes the station of the radio until a popular Japanese song is heard. This music in turn seamlessly plays into the next scene where Leitzu is having her picture taken in a photograph studio. The setup and atmosphere of the place is a nostalgic reconstruction of a photo studio in the late 1930s or early 1940s complete with the appropriate backdrop and paraphernalia. The melody on the soundtrack complements Leitzu's gentle allure but it also serves as a reminder of the complexity of Taiwanese history and culture. It is interesting to note that even though Japan had been the colonial master of Taiwan since 1895, it is not until this sequence set during World War Two that the Japanese presence becomes more pronounced. This change reflects the fact that before 1937, Japanese occupation of Taiwan was one of relative benevolence, but when the second Sino-Japanese war broke out, Japan intensified police repression and forced assimilation on the island. ${ }^{(13)}$

With regard to how the Chinese traditionally expressed their emotions, the portrayal of the affair between Li and Leitzu is particularly instructive. In one of the most charming scenes in the film, Leitzu puts Li's loyalty to the test by pretending to be away while one of her friends offer to spend the night with him. Li fortuitously refuses. When Leitzu reappears in their room, few words are exchanged between them but the atmosphere is charged with a complexity of mock indignation and affection. In place of words, every little gesture and expression gains significance. With an intuitive understanding, the director shows Leitzu tenderly asking Li if he has enough money for himself. As the director puts it, "The Chinese people have always gone about a tortuous and roundabout route in expressing emotions." The keynote is restraint, emphasized by the consistent medium-long shot of the scene, the absence of close-ups or subjective shots. The viewer feels like a privileged but impartial observer of a highly intimate scene. Moments later, Leitzu's "sisters" arrive for a dinner in their room. The mood is convivial and the dinner table lit by the lamp above the table creates a sense warmth, security and friendship.

With the image of this dinner on-screen, Li recalls an episode of how Leitzu had followed him to another town against his wishes. Not long after their return to the Cherry Garden brothel, Leitzu developed a sore on her lip which would have been fatal had it not been for him. The film cuts to the narrator himself on the bed of the same room in the brothel. We hear of how he and Leitzu became increasingly closer after he had saved her life. Nevertheless, he decided to go back to his wife and family in Taipei. This time his loyalty worked against Leitzu. Li explains his decision: "We were travellers who met on a path. I saw her getting married to someone else. But when I told her this, she called me insincere..." This episode, which may seem callous on Li's part, illustrates his deeply-rooted Confucian principles. Though Li was happy with his mistress, he had no doubt where his ultimate duty and loyalty was. According to director Hou, "People from that age would tackle problems with flexibility but from a strong principled position. Life and death and social relationships are to them straightforward propositions." Whether this statement is too much of a generalisation is a question, but it does seem true that $\mathrm{Li}$ "embodies values such as filial piety, loyalty and frugality." (14)

The beginning of the final third of the film also deals with the virtue of loyalty but from the skewed perspective of war propaganda. In this sequence, the elliptical narrative structure highlights the ambivalence between propaganda in drama and propaganda in life. Against an extreme long shot of a band of men in uniform crossing a bridge over a ravine, a voice intones in Japanese: "The remains of Dokisan, radio operator for the Japanese army come back to his native Taiwanese village." The camera cuts to another extreme long shot of a mountainous setting in daylight. A small crowd on the plain is gathered in front of a white tent with the Japanese flag and banners. The same voice continues to praise Dokisan for his bravery and loyalty to the Japanese empire. 
Although this is supposedly a funeral, its propaganda function and histrionics produce a sense of unreality. How false it rings is ironically captured in the next shot showing the backstage of the puppet theatre where $\mathrm{Li}$ is now the chief puppeteer of the "Taipei Propaganda Troupe for the Defeat of America and England." The puppeteers are putting on a play about the heroism of Dokisan, who sacrificed his life for the Japanese Empire. Where before, the exquisitely-fashioned hand puppets, each stood for identifiable personalities, there are only faceless representations of soldiers here. Nevertheless, the story and the skill of the puppeteers find their audience. When the camera cuts to another extreme long shot revealing that it is evening, we see that the puppet theatre scene is taken from the reverse angle of the funeral shot. Set in the same landscape with the same crowd watching each event, the two scenes are mirror images of each other - in function and effect.

In this segment of the film the director also shows Li's experiences with the Japanese. On one occasion, Li gets into a fight with a drunken Japanese officer who had behaved boorishly. The fight is filmed in an extreme long shot thus physically distancing the viewer from the action. Hou has remarked that "a screen holding a long-shot has a certain kind of tension, and for this you can't find an alternative method to substitute."(15) The tension may be partly due to the fact that it is the same perspective we have when observe events happening at a distance in real life. Distance can create a sense of unreality and ambiguity even though things are happening before our eyes. When this incident is brought before the authorities, the Japanese Chief of Police finds Li justified. The image of the former as fair and humane is reinforced in his handling of the problem involving Li's son who was caught trying to sell Ayu fish which was banned at the market. The police chief took the trouble of going to the river where Li's son had been fishing and found that the Ayu fish ate the same bait that the boy had used. Thus he believed the boy had not caught the fish on purpose.

This story comes to light at dinner time that night as the family sits in Japanese fashion on the floor around a low table. They are being housed in a police dormitory. Carefully composed and lit in the style of yet another tableau, the viewer once again seems to be looking discreetly through a window. Hou tends to emphasize the geometric design in his interior shots, a preference clearly evident here. In this scene, the shapes and lines of the window and doors, and the designs on the windows themselves seem to bar in the inhabitants of the house. As they speak the lights suddenly go out and the sirens wail.

The next few scenes remain oblique: we see $\mathrm{Li}$ and a Japanese friend bidding each other farewell followed by an outdoors shot showing Li's family on the move and finally settled in the cluttered, gloomy interior of a coffin shop. In this new environment, Li's father-in-law becomes ill with malaria. Only at this point is the viewer informed through Li's voice-over narration about the meaning of the events. We find out that the family has been evacuated to a remote village because of enemy air raids on Taipei. Upon reaching their destination, they were told that Japan had surrendered but because they could not get train tickets home, they had to stay at their designated shelter, a coffin shop. There, members of the family fell victim to malaria, eventually causing the death of Li's father-in-law. Peggy Chiao makes this astute observation on Hou's use of ellipsis in The Puppetmaster:

...the elliptical economy of its structure is in total contrast to the Western understanding of aesthetics. Invariably, the audience is in a state of confusion in the beginning, not knowing cause and effect. It is only when Li Tien-luk's monologue occurs that the audience suddenly recovers its sense of comprehension, and can retrieve the meaning of what had transpired before... The whole experience of watching the film is a continuous process of exchange - a communication with the film itself. The burden it imposes is of course something that many audiences would find hard to accept. ${ }^{(16)}$

Back in their family home in Taipei, Li is asked to perform again for his audiences, even though he is stricken with malaria. At one point during his performance, he suffers a severe attack and has to be helped off the stage to rest. For the surprised spectators, this is an instance of when the drama backstage becomes more interesting than the play itself.

The film cuts to a landscape shot with a faint echo of a hammer. In the next shot, Li's wife is crying beside a small body covered by a blanket. The sound of boards being hammered is now unmistakable. It is only in the next shot that the source of the sound is revealed: Li and his elder son are in the courtyard making a coffin, a fact confirmed by the narrator. Li's younger son had contracted malaria through his mother's milk and had died. Li's attitude to the son's death is resigned but pragmatic. Considering the death as fate, he 
asks a Taoist priest to bury the son for a quick rebirth.

An intriguing distancing device is employed during this voice-over narration. While Li and his son are making the coffin in the courtyard, a figure which seems almost certainly to be the real Li Tienlu walks into the scene and sits down in the background, observing the pair at work. By simply suggesting the actual presence of the narrator in the background, the stability of the scene's cinematic "truth" is shaken. Furthermore, this technique of meta-cinema weaves together the film's interlacing themes of past and present, memory and reality, life and its dramatic representation, fate and human action. In the next shot, we indeed find $\mathrm{Li}$ the narrator in front of the courtyard seated in a huge antique chair relating how he saved some Japanese soldiers from being beaten to death. On another occasion, he discovers that his audiences are paying for his performances by selling the scrap metal from sabotaged planes.

The final scene also produces one of the most illuminating and symbolic images in the film. Set in the open sunlit fields, we see the resourceful citizens of Taipei perched on the warplanes, busily dismantling the machines for scrap metal so as to pay for Li's performances which they believe will please and thank the gods. Li declares, "And that's the reason why Taiwan was finally liberated from Japan." It is essentially a positive image showing the triumph of freedom over oppression and a people able to take charge of their lives again.

The Puppetmaster is a film by a director who not only respects but is genuinely seeking to understand the authenticity of Chinese culture and its philosophy through his subject and friend, the puppeteer Li Tienlu.

In searching for a narrative structure that would illuminate the values, attitudes and emotional expression of his culture, Hou Hsiao-hsien has discovered his inspiration in the Chinese traditional arts. Through Hou's reimagination of ellipsis for the film medium, enhanced by the subtle beauty of the images, The Puppetmaster is an impressive achievement in which the message is well-served by the medium.

\section{Notes}

1. Peggy Chiao, "History's Subtle Shadows," Cinemaya 21, Autumn 1993, p. 5.

2. J. Hoberman, "The Puppetmaster", Village Voice, 12 October 1993, p. 50.

3. Chiao. p. 8.

4. Michel Ciment, "Entretien avec Hou Hsiao Hsien," Positif No. 394, December 1993, p. 11.

5. Chiao, p. 8-9. 6. Chiao, p. 9. 7. Chiao, p. 7.

8. Graham Parkes, "Japanese Philosophy," The Oxford Companion to Philosophy, Oxford: New York, 1995 ed.

9. Michael Sullivan, The Arts of China (Berkeley: University of California Press, 1984), 156.

10. Sullivan, 156.

11. Wolfram Eberhard, A Dictionary of Chinese Symbols, (Routledge: London, 1986), p. 267.

12. Chiao, p. 7.

13. John K. Fairbank et al., East Asia: Traditions and Transformation (Houghton: Boston, 1989), p. 900.

14. Chiao, p. 4.

15. Abe Mark Nornes and Yeh Yueh-yu, "City of Sadness," http://cinemaspace.berkeley.edu/Papers/CityofSadness/slscu.htm

16. Chiao, p. 9.

\section{References}

\section{Bibliography}


Amiel, Vincent. "Le Maître de marionettes." Positif, No.394, December 1993, 8-9.

Bassan, Raphaël. "Le Maître de marionettes." Le Mensuel du cinéma, No. 12, December 1993, 27.

Canby, Vincent. "A Taiwan Artist Tells His Island's Story Obliquely." New York Times, 6 October 1993, p. C19.

Chiao, Peggy. "History's Subtle Shadows." Cinemaya 21, Autumn 1993, 4-11.

Ciment, Michel. "Entretien avec Hou Hsiao Hsien." Positif, No.394, December 1993, 10-14.

Eberhard, Wolfram. A Dictionary of Chinese Symbols. Routledge: London, 1986.

Elley, Derek. "Hsimeng Rensheng (The Puppetmaster)." Variety, 351, 7 June 1993, 38-39.

Fairbank, John K., et al. East Asia: Traditions and Transformation. Houghton: Boston, 1989.

Gauthier, Guy. "Hou Hsiao-Hsien l'héritier." Le Mensuel du cinéma, No. 12, December 1993, 28-29.

Hoberman, J. "Chinese Connection." Village Voice, 12 October 1993, 50-52.

Jousse, Thierry. "Entretien avec Hou Hsiao Hsien." Cahiers du cinéma, No. 474, December 1993, 44-45.

Kemp, Philip. "Hsimeng Rensheng (The Puppetmaster)." Sight and Sound, 4, No. 6, June 1994, 51-52.

Morice, Jacques. "La mémoire impressionée." Cahiers du cinéma, No. 474, December 1993, 40-43.

Niogret, Hubert. "Hsimeng Rensheng." Positif, No.389/390, July/August 1993, 46-47.

Nornes, Abe Mark and Yeh Yueh-yu, "City of Sadness," http://cinemaspace.berkeley.edu/Papers/Cityof Sadness/slscu.html

Parkes, Graham. "Japanese Philosophy," The Oxford Companion to Philosophy, Oxford: New York, 1995 ed.

Rauger, Jean-François. "Naissance d'une nation." Cahiers du cinéma, No. 469, June 1993, 18.

Romney, Jonathan. "The Puppetmaster." New Statesman, 13 May 1994, 34.

Stanbrook, Alan. "The Worlds of Hou Hsiao-Hsien." Sight and Sound, 59, No. 2, Spring 1990, 120-124.

Sullivan, Michael. The Arts of China. Berkeley: University of California Press, 1984. The underlying intention of the film is, according to the director, to emphasize the emotional states of the characters, their relationships, and the nature of life. (Positif)

\section{Author Information}

Yvonne NG is the co-author of Latent Images: Film in Singapore Second edition (NUS Press, 2010); Latent Images: Film in Singapore (OUP, 2000) and Latent Images: Film in Singapore CD-ROM (Singapore, 2003). She has written on Singapore and Asian cinema and contributes to the International Film Guide. 